\title{
Selectivity of Proteinuria in Childhood Nephrotic Syndrome
}

\author{
DAVID R. LINES \\ From the Department of Child Health, University of Adelaide, Adelaide Children's Hospital, North Adelaide, \\ South Australia
}

In 1960, Blainey et al. introduced the concept that in proteinuria the glomerulus retained a filtering action. They showed that the clearance of a particular protein was inversely proportional to its molecular weight. Thus, small molecular weight proteins were cleared more readily than the large ones. This property they called 'selectivity'. They further showed that if this selectivity was of a high order, the prognosis and response to steroids in the nephrotic syndrome were good.

Other workers have now established that selectivity of proteinuria is of use in predicting the response to corticosteroids in the nephrotic syndrome (Joachim et al., 1964; Cameron and White, 1965). Selectivity may be defined as the slope of the regression line relating the logarithm of renal clearance of proteins relative to that of transferrin, to the logarithm of their molecular weights. If such a regression is steep, the proteinuria is said to be highly selective, and response to corticosteroids is likely to be good.

The nephrotic syndrome is a frequent disorder in childhood, but only one previous report (Cameron and White, 1965) has dealt with selectivity of proteinuria in childhood nephrotic syndrome.

\section{Material and Methods}

Studies were made on 26 patients, between 2 and 14 years, admitted with the nephrotic syndrome to the Adelaide Children's Hospital between April 1966 and April 1968. The criteria of 'nephrotic syndrome' were: gross proteinuria, hypoproteinaemia, and oedema.

The urinary concentration of 5 proteins, orosomucoid (mol. weight 40,000), albumin (mol. weight 67,000), transferrin (mol. weight 88,000), IgG (mol. weight 150,000 ), and $a_{2}$-macroglobulin (mol. weight 840,000 ), were measured by immunodiffusion. The technique was the Soothill modification of the Ouchterlony method; commercial antisera placed in wells in 'homemade' agar plates or commercially prepared immunodiffusion plates (Hoechst) were used. The values so

Received January 6, 1969. obtained for the urinary concentration of each protein were divided by the plasma concentration of the same protein to give the appropriate $U / P$ value; the $U / P$ value for the individual proteins was compared with that for transferrin and expressed as a percentage. These percentages were then plotted on logarithmic paper, against the molecular weight. The slope of the resultant regression line was obtained by the method of least squares. This value $(\theta)$ was used as a measure of the selectivity of the proteinuria. Typical examples are shown in Fig. 1 and 2.

All patients in the trial were treated with initial high-dose $(40 \mathrm{mg}$. prednisolone per day or equivalent) corticosteroids and bed-rest. Most were also given penicillin and a high-protein diet. Salt and water restriction was dependent on the clinic to which they were admitted.

The patient was considered to have responded to corticosteroid administration if there was a disappearance of clinical signs and symptoms, and the 24-hour urinary protein fell below $50 \mathrm{mg}$. All patients who thus responded had at least one period of remission of greater than 3 months. Failure of response was defined as persistence of clinical signs and symptoms, with a 24-hour urinary protein of greater than $500 \mathrm{mg}$.

The histological diagnosis was made from percutaneous renal biopsy samples. These samples were examined by light microscopy only. The stains used were haematoxylin and eosin, Mallory's trichromate, and periodic acid silver. The diagnoses in Table I were taken from the routine reports on such samples, which were provided without knowledge of the selectivity studies. It can be seen from Table II that not all points fall exactly on a straight line. This is to be expected when there is a coefficient of variation in measuring protein level in serum by the immunodiffusion technique. Soothill (1962) showed an average coefficient of variation from 14 to 25 depending on the protein estimated. The coefficient of variation for transferrin was found to be 15 by the technique used in this experiment.

That the relation is a linear one is strongly suggested by the correlation coefficient determined in each patient so that the line could be plotted by the methods of least squares. This correlation coefficient was greater than $-0 \cdot 85$ in all but 5 cases. 


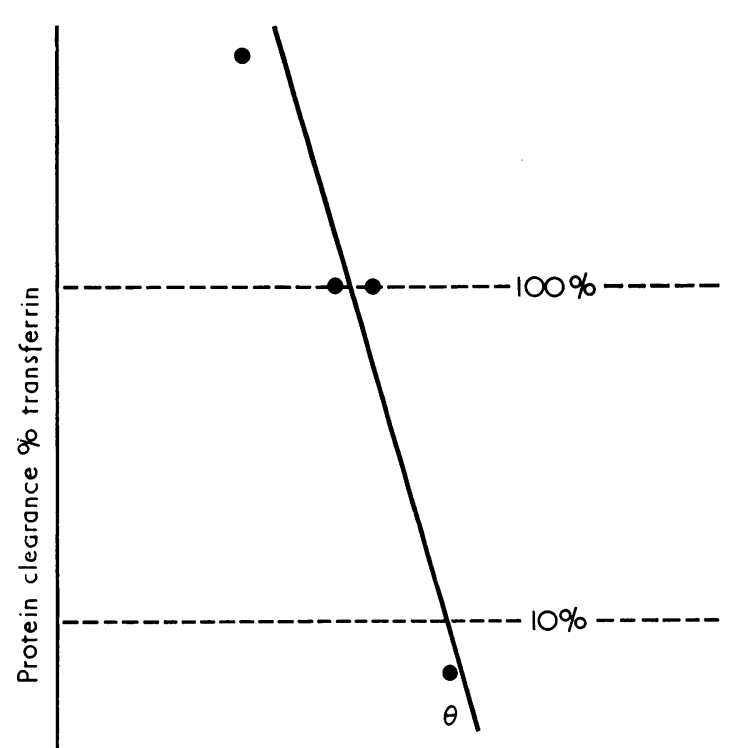

$\theta=74^{\circ}$

Proteinuria is

highly selective

Molecular weight $\times \frac{1}{10,000}$

Fig. 1.-Case 4. Protein clearance expressed as a percentage of transferrin clearance is plotted on a logarithmic scale on the ordinate. Molecular weight divided by 10,000 is plotted on the abscissa.

The regression line makes an angle of $74^{\circ}$ with the horizontal and the proteinuria is said to be highly selective.

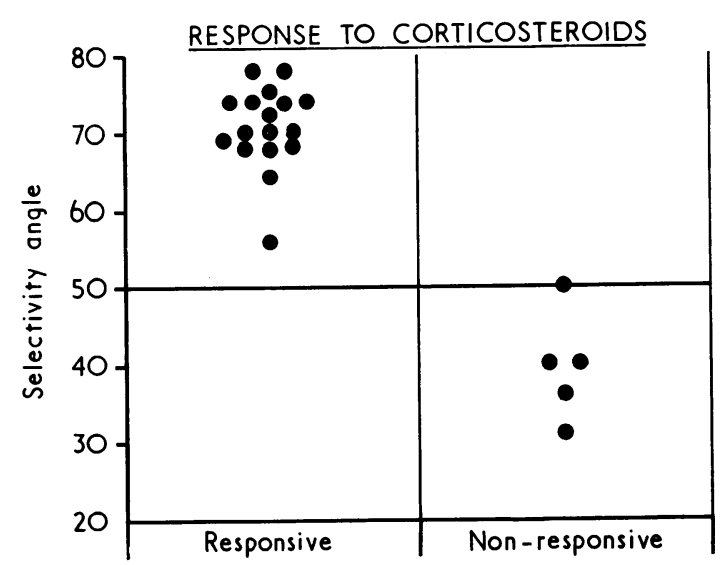

FIG. 3.-Selectivity angles of 17 children with the nephrotic syndrome which responded to corticosteroids, compared with 5 children whose nephrotic syndrome did not respond.

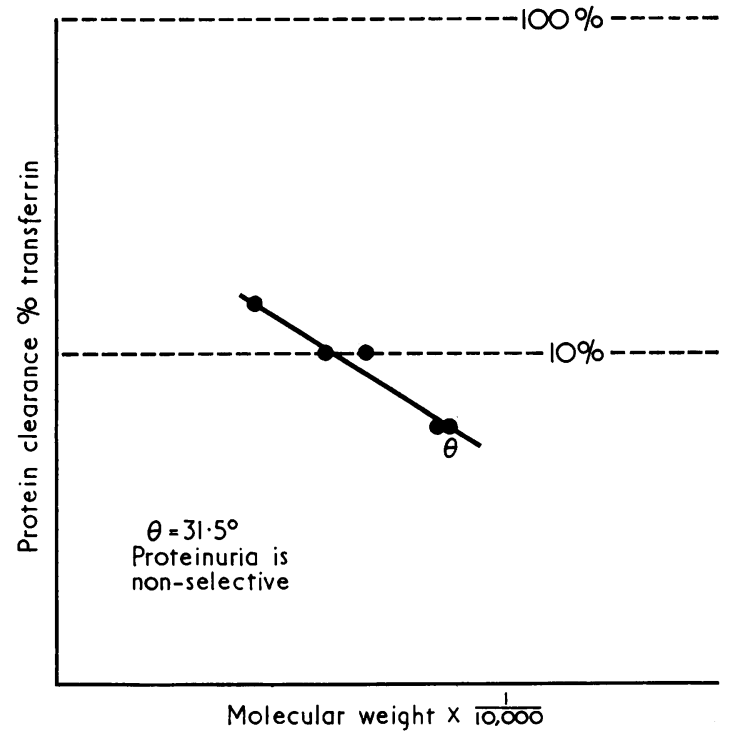

FIG. 2.-Case 25. Protein clearance is plotted against molecular weight as in Fig. 1. The angle of selectivity is $31 \cdot 5^{\circ}$. This child deteriorated when given prednisolone.

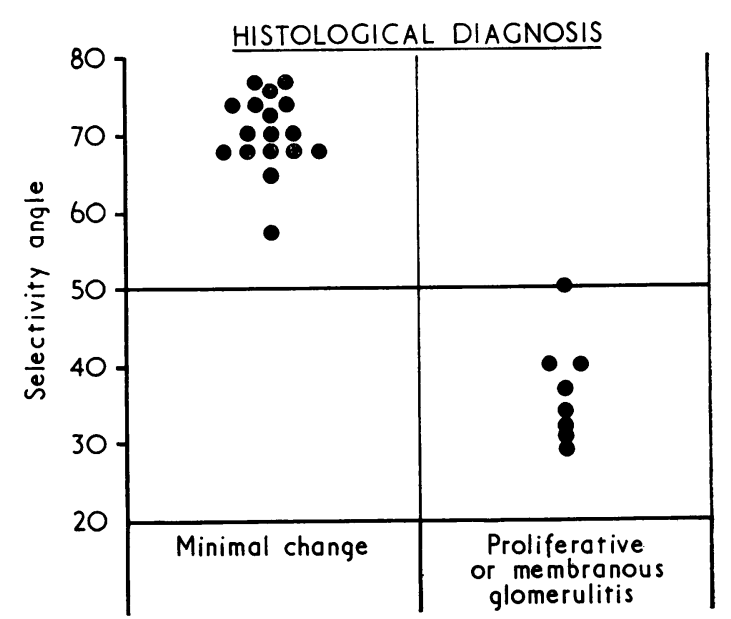

FIG. 4.-Selectivity angles of children with the nephrotic syndrome, in which renal biopsy revealed 'minimal lesion', are compared with those of children with nephrotic syndrome, in association with glomerulonephritis found in renal biopsy. 
Because of this variation in repeated readings a line through 4 or 5 points is preferred to a ratio between two proteins, as used by Cameron and Blandford (1966) and MacLean and Robson (1967).

\section{Results}

The results are summarized in Table I. It can be seen that all patients with a selectivity regression angle of greater than $50^{\circ}$ responded to corticosteroids, while those at or below $50^{\circ}$ did not. The mean angle for the steroid-responsive group was $66 \cdot 6^{\circ}$, SD $6 \cdot 1^{\circ}$. In the non-responsive group, the mean angle was $36 \cdot 6^{\circ}, \mathrm{SD} 6 \cdot 2^{\circ}$.

A correlation with the histological diagnosis can be noted, those patients with minimal changes by light microscopy having higher selectivity of proteinuria than those who had obvious pathology. These results are expressed in graphical form in Fig. 3 and 4.

$50^{\circ}$ is chosen as an arbitary dividing line because it falls below the mean of the responsive group less $2 \mathrm{SD}$ and above the mean of the non-responsive group plus $2 \mathrm{SD}$.

\section{Discussion}

This study shows that measuring the selectivity of proteinuria is of value in childhood nephrotic syndrome. Cases with high selectivity responded well to steroid therapy, and high selectivity correlated with a minimal change in histological appearance. The test outlined thus provides a useful guide to management, and potentially could reduce the number of renal biopsies carried out in these children. This avoids the slight but definite risk of the procedure, and in addition the selectivity test can be carried out in those children who have severe hypertension or a haemorrhagic tendency (Handley and Lawrence, 1967) in whom renal biopsy is contraindicated. It has been claimed (Joachim et al., 1964) that, in adults, protein selectivity provides a better guide to the steroid response than renal biopsy; the present study suggests that, for children, these two techniques are at least of equal value in assessing the likelihood of steroid response.

\section{Summary}

Studies of selectivity of proteinuria in childhood nephrotic syndrome in 26 patients are presented. A good correlation between high selectivity, expressed as a regression angle of greater than $50^{\circ}$, and steroid response, is demonstrated.

Thanks are due to the Honorary Staff, the Adelaide Children's Hospital, for their co-operation in this study, and to Dr. M. Fowler and Dr. R. Carter, Pathology

\section{TABLE I}

Correlation of Selectivity of Proteinuria with Response to Corticosteroids and Histological Diagnosis

\begin{tabular}{|c|c|c|c|c|}
\hline Case No. & $\begin{array}{l}\text { Age } \\
\text { (yr.) }\end{array}$ & $\begin{array}{l}\text { Selectivity Angle } \\
\text { (degrees) }\end{array}$ & Renal Histology & Response to Steroid \\
\hline $\begin{array}{r}1 \\
2 \\
3 \\
4 \\
5 \\
6 \\
7 \\
8 \\
9 \\
10 \\
11 \\
12 \\
13 \\
14 \\
15 \\
16 \\
17 \\
18 \\
19 \\
20 \\
21 \\
22 \\
23 \\
24 \\
25 \\
26\end{array}$ & $\begin{array}{r}7 \\
10 \\
4 \\
7 \\
14 \\
6 \\
4 \\
9 \\
8 \\
5 \\
6 \\
7 \\
3 \\
14 \\
11 \\
6 \\
12 \\
8 \\
11 \\
12 \\
10 \\
14 \\
13 \\
7 \\
8 \\
11\end{array}$ & $\begin{array}{l}77 \\
77 \\
75 \\
74 \\
74 \\
74 \\
74 \\
72 \\
70 \\
70 \\
70 \\
69 \\
69 \\
69 \\
69 \\
68 \\
64 \\
57 \\
50 \\
40 \\
40 \\
37 \\
33 \\
32 \\
31 \\
30\end{array}$ & $\begin{array}{l}\text { Minimal change } \\
\text { Minimal change and ureteric reflux } \\
\text { Minimal change } \\
\text { Minimal change } \\
\text { Minimal change } \\
\text { Not available } \\
\text { Minimal change } \\
\text { Minimal change } \\
\text { Minimal change } \\
\text { Minimal change } \\
\text { Minimal change } \\
\text { Minimal change and nephroblastoma } \\
\text { Minimal change } \\
\text { Minimal change } \\
\text { Minimal change } \\
\text { Minimal change } \\
\text { Minimal change } \\
\text { Minimal change } \\
\text { Membranous glomerulonephritis and ureteric reflux } \\
\text { Proliferative glomerulonephritis } \\
\text { Polyarteritis nodosa, severe glomerulitis } \\
\text { Disseminated lupus, severe glomerulitis } \\
\text { Proliferative glomerulonephritis } \\
\text { Membranous glomerulonephritis } \\
\text { Proliferative glomerulonephritis } \\
\text { Proliferative glomerulonephritis }\end{array}$ & $\begin{array}{l}\text { Yes } \\
\text { Yes } \\
\text { Yes } \\
\text { Yes } \\
\text { Yes } \\
\text { Yes } \\
\text { Yes } \\
\text { Yes } \\
\text { Yes } \\
\text { Yes } \\
\text { Yes } \\
\text { Yes } \\
\text { Yes } \\
\text { Yes } \\
\text { Not used } \\
\text { Yes } \\
\text { Yes } \\
\text { Yes } \\
\text { No } \\
\text { No } \\
\text { No } \\
\text { No } \\
\text { Not used } \\
\text { Not used } \\
\text { No } \\
\text { Not used }\end{array}$ \\
\hline
\end{tabular}


TABLE II

Urine to Plasma $(U / P)$ Ratio for Individual Proteins and this U/P Ratio as Percentage of Transferrin U/P

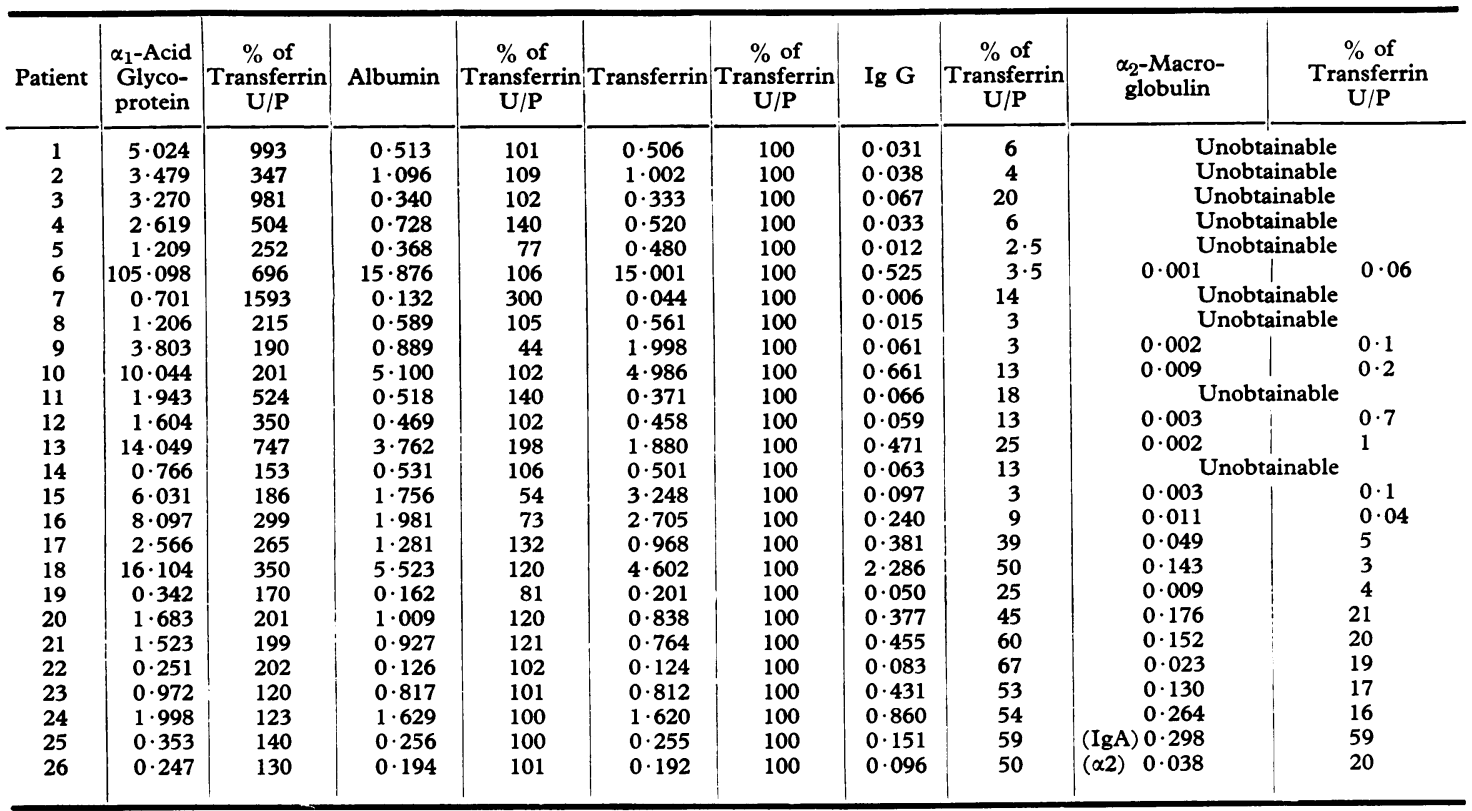

Department of the Adelaide Children's Hospital, for their reports on renal biopsies; and to Dr. J. R. Lawrence and Professor G. M. Maxwell for their help and encouragement throughout the past 2 years. The research was supported by a grant from the Adelaide Children's Hospital Research Trust. Antisera and partigen immunodiffusion plates were supplied by Australian Hoechst.

\section{REFERENCES}

Blainey, J. D., Brewer, D. B., Hardwicke, J., and Soothill, J. F. (1960). The nephrotic syndrome. Quart. F. Med., 29, 235.

Cameron, J. S., and Blandford, G. (1966). The simple assessment of selectivity in heavy proteinuria. Lancet, 2, 242.
, and White, R. H. R. (1965). Selectivity of proteinuria in children with the nephrotic syndrome. ibid., 1, 463.

Handley, D. A., and Lawrence, J. R. (1967). Factor-IX deficiency in the nephrotic syndrome. ibid., 1, 1079.

Joachim, G. R., Cameron, J. S., Schwartz, M., and Becker, E. L. (1964). Selectivity of protein excretion in patients with the nephrotic syndrome. F. clin. Invest., 43, 2332.

MacLean, P. R., and Robson, J. S. (1967). A simple method for determining selectivity of proteinuria. Lancet, 1, 539.

Soothill, J. F. (1962). Estimation of eight serum proteins by gel diffusion precipitin technique. F. Lab. clin. Med., 59, 859.

Correspondence to Dr. D. R. Lines, Department of Child Health, The Adelaide Children's Hospital, Inc., North Adelaide, South Australia. 